\title{
Catalyst-Free Synthesis of Hollow-Sphere-Like ZnO and Its Photoluminescence Property
}

\author{
Junye Cheng, ${ }^{1}$ Xiuying Yang, ${ }^{2}$ Hua Tian, ${ }^{2}$ Bin Zhao, ${ }^{3}$ and Deqing Zhang ${ }^{2}$ \\ ${ }^{1}$ School of Energy and Power Engineering, University of Shanghai for Science and Technology, Shanghai 200093, China \\ ${ }^{2}$ Key Laboratory of Fine Chemicals of College of Heilongjiang Province, Qiqihar University, Qiqihar 161006, China \\ ${ }^{3}$ School of Materials Science and Engineering, University of Shanghai for Science and Technology, Shanghai 200093, China
}

Correspondence should be addressed to Bin Zhao; zhaobin@usst.edu.cn and Deqing Zhang; zhadqing@163.com

Received 3 May 2014; Revised 6 June 2014; Accepted 8 June 2014; Published 23 June 2014

Academic Editor: Yong Ding

Copyright (C) 2014 Junye Cheng et al. This is an open access article distributed under the Creative Commons Attribution License, which permits unrestricted use, distribution, and reproduction in any medium, provided the original work is properly cited.

\begin{abstract}
Hollow-sphere-like $\mathrm{ZnO}$ was successfully prepared by a facile combustion route at $950^{\circ} \mathrm{C}$, and no external catalysts or additives were introduced. The morphology and structure of the hollow-sphere-like $\mathrm{ZnO}$ were characterized by X-ray diffraction (XRD), scanning electron microscopy (SEM), high-resolution transmission electron microscopy (HRTEM), and energy dispersive spectrometer (EDS). The possible growth mechanism was discussed in detail. In addition, the as-obtained hollow-sphere-like $\mathrm{ZnO}$ exhibited a strong green emission at $518 \mathrm{~nm}$ and a weak UV emission at $385 \mathrm{~nm}$. We believe that the hollow-sphere-like ZnO material may be a good candidate for application in optical devices and catalyst systems.
\end{abstract}

\section{Introduction}

In recent years, one of the important goals of material scientists has been developing ways of tailoring the structure of materials to obtain specific nanomorphologies $[1,2]$. The shape and size of inorganic nanomaterials are well known to have an important influence on their physical properties [3], also important in various applications such as catalysis, solar cells, light-emitting diodes, and biological labelling.

Zinc oxide $(\mathrm{ZnO})$, as a material with large exciton binding energy $(60 \mathrm{meV})$ and wide gap energy $(3.2 \mathrm{eV})$ at room temperature, has gained substantial interest in the research community because of some excellent properties, such as field emission [4], optics [5], piezoelectricity [6], microwave absorption $[7,8]$, and the dynamic mechanical property [9]. In particular, nanostructured $\mathrm{ZnO}$ has various important applications in electronics and bioscience, that is, fieldeffect transistor [10], light-emitting diodes [11], chemical and biosensor [12], varistors [13], solar cells [14], and so on. No doubt, it will be widely used in various scientific and technical fields in the future.
Up to now, abundant $\mathrm{ZnO}$ nanostructures including nanowires [15], nanorods [4], tetraneedle whiskers [9], nanobelts [16], nanotubes [17], and nanorings [10] have been successfully synthesized by various methods, such as chemical vapor deposition [18], thermal evaporation [19], hydrothermal methods [20], electrochemical deposition [21], and template-based growth [22]. However, during the synthesis of unique $\mathrm{ZnO}$ nanostructures, the use of template, catalysts, or additives is usually necessary condition, and the synthesis process is complex sometimes [23-25]. Deng and coworkers [26] synthesized the novel $\mathrm{ZnO}$ hollow spheres by first adsorbing zinc ions onto the surfaces of sulfonated polystyrene core-shell template spheres, then adding $\mathrm{NaOH}$ to form a $\mathrm{ZnO}$ crystal nucleus, and final making $\mathrm{ZnO}$ crystal nucleus grow at proper temperature.

In this paper, hollow-sphere-like $\mathrm{ZnO}$ was successfully prepared by a facile combustion route in atmosphere, and no external catalysts or additives were introduced. The morphology and structure analyses of the hollow-sphere-like $\mathrm{ZnO}$ were presented. We explained the mechanism based on the unique growth process of the hollow-sphere-like $\mathrm{ZnO}$ and 


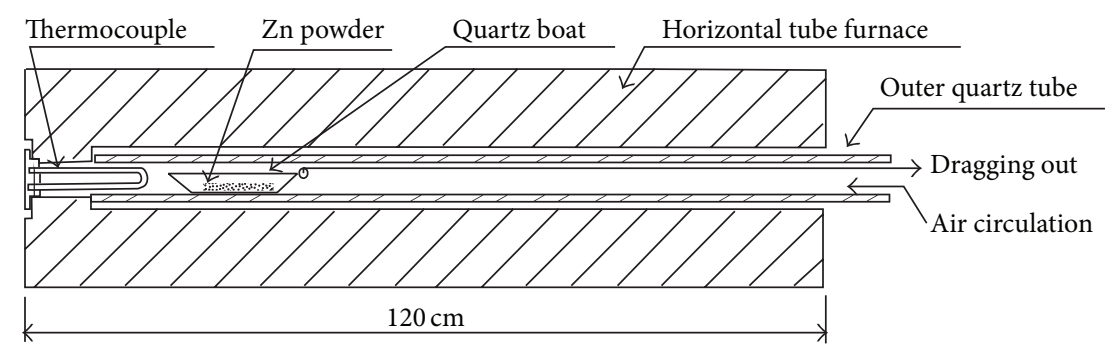

FIgURE 1: The schematic illustration of experimental setup for the growth of $\mathrm{ZnO}$.

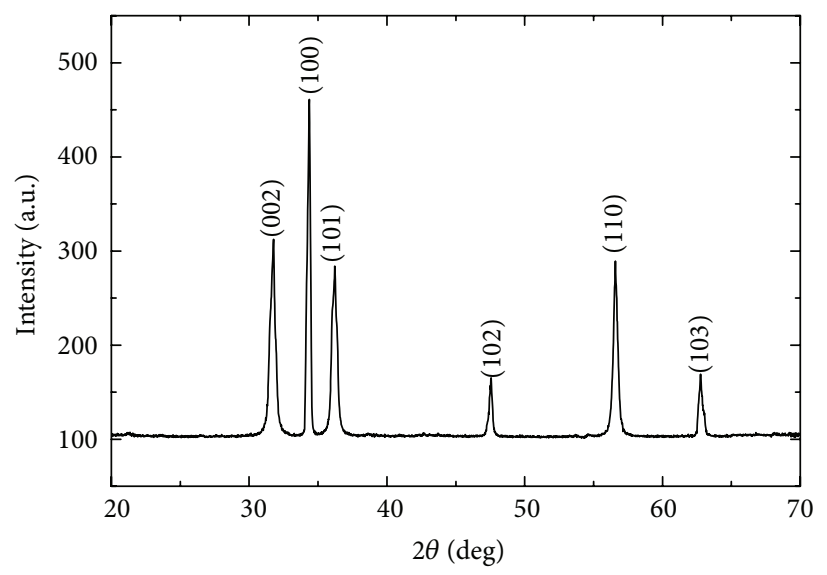

Figure 2: Powder X-ray pattern of the as-obtained product.

the relevant characterization data. The photoluminescence properties of the as-prepared crystals were also investigated.

\section{Experimental}

Hollow-sphere-like $\mathrm{ZnO}$ samples were prepared by a simple combustion oxidation approach at $950^{\circ} \mathrm{C}$ in a horizontal tube furnace (inner diameter $10 \mathrm{~cm}$ and length $120 \mathrm{~cm}$ ). The schematic illustration of the experimental setup is shown in Figure 1. No catalysts or carrier gases were used. In the typical procedure, zinc powder (melting point $419^{\circ} \mathrm{C}$, particle size $<2 \mu \mathrm{m}$, and purity $99.999 \%$ ) was put into a small quartz boat. The quartz boat was entered into the proper position of the tube furnace (one end of the tube was closed), and the furnace temperature was ramped to $950^{\circ} \mathrm{C}$. The quartz boat remained in the heating zone for 2 minutes and then it was slowly dragged out from the furnace. The samples were naturally cooled down in ambient conditions. The structure of the products was analyzed using X-ray diffraction (XRD, Advance D8). The morphology and size distribution of the products were investigated by scanning electron microscopy (SEM, S-4300). High-resolution transmission electron microscopy (HRTEM) image was obtained on a JEOL-2010 TEM at an acceleration voltage of $200 \mathrm{kV}$. Photoluminescence (PL) spectrum was obtained using a Fluoro Max-2 fluorescence spectrophotometer (Jobin Yvon company) with Xe light as the excitation source $(320 \mathrm{~nm})$. All the measurements were carried out at room temperature.

\section{Result and Discussion}

The as-obtained product was characterized by XRD. The XRD pattern is shown in Figure 2 and the Miller indices are indicated for each diffraction peak. The diffraction peaks can be well indexed to the standard, the hexagonal wurtzite structure of $\mathrm{ZnO}$. The calculated lattice constants were $a=$ $0.3249 \mathrm{~nm}$ and $c=0.5206 \mathrm{~nm}$, which are in good agreement with the JCPDS file of $\mathrm{ZnO}$ (JCPDS number 36-1451). The strong and clear peaks reveal the high purity and crystallinity of the as-obtained product. No characteristic peaks were observed for other impurities.

The products of hollow-sphere-like $\mathrm{ZnO}$ were obtained through typical procedure above, after $\mathrm{Zn}$ powder was kept in furnace of $950^{\circ} \mathrm{C}$ for 2 minutes and dragged out of furnace in 10 seconds. Figure 3 presents relevant images of hollowsphere-like ZnO. From the SEM image (Figure 3(a)), the morphology of the as-obtained $\mathrm{ZnO}$ is nearly spherical, while a portion of $\mathrm{ZnO}$ spheres could not be clearly observed due to their small size distribution. The amplified SEM images of the hollow-sphere-like $\mathrm{ZnO}$ show clearly that the diameter of these spheres range from $\sim 2 \mu \mathrm{m}$ to $\sim 15 \mu \mathrm{m}$, as shown in Figures 3(b) and 3(c). Careful observation of some spheres shows that they possess rough structures with small particles, pores, or holes. Furthermore, some broken egg-shell-like $\mathrm{ZnO}$ residue structures can be found in Figure 3(b) as shown by arrows. In Figure 3(c), there is apparently a ringent $\mathrm{ZnO}$ hollow sphere, which provided an opportunity to see the "opened" structure. To shed 


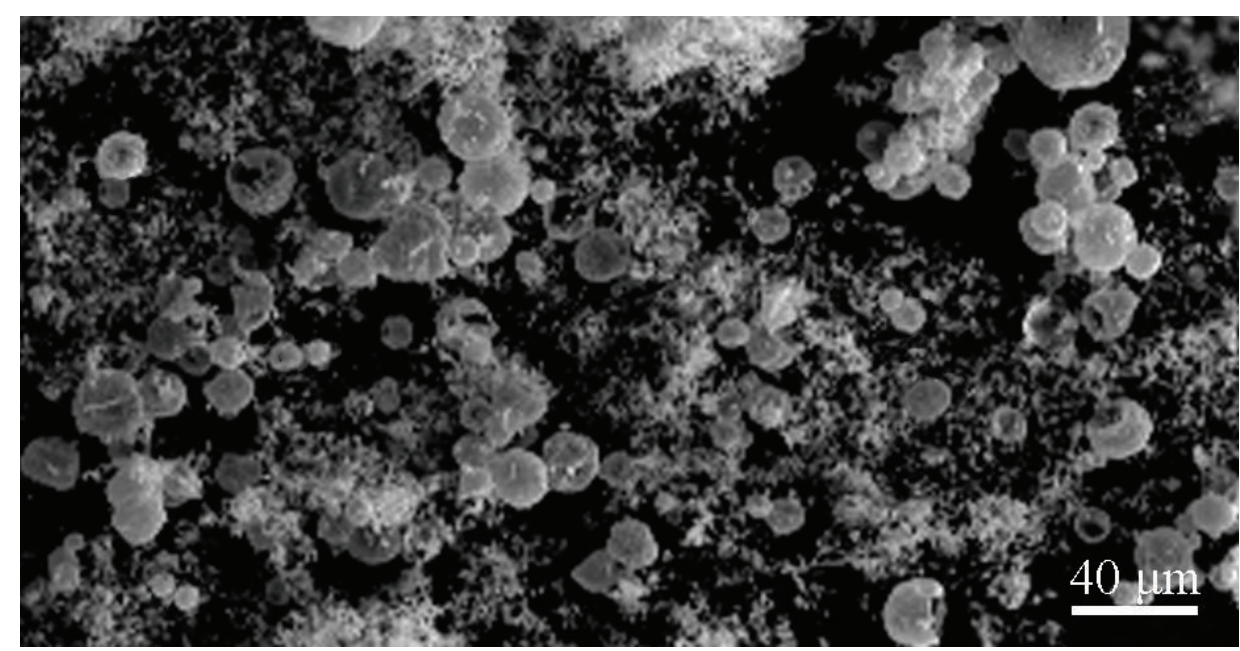

(a)

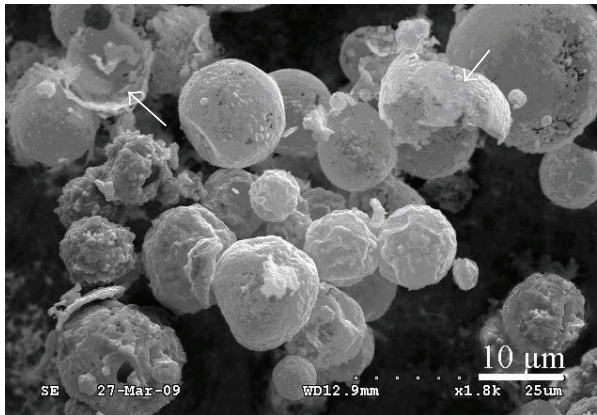

(b)

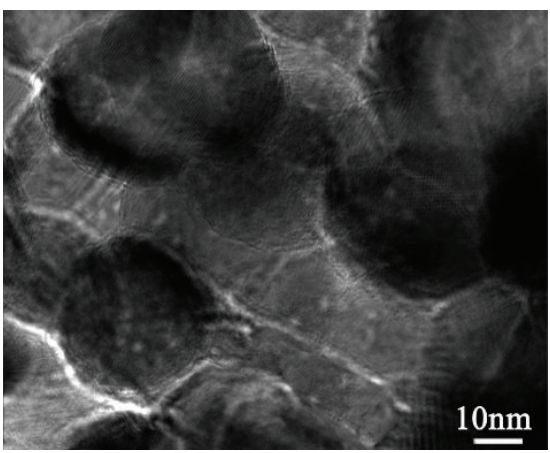

(d)

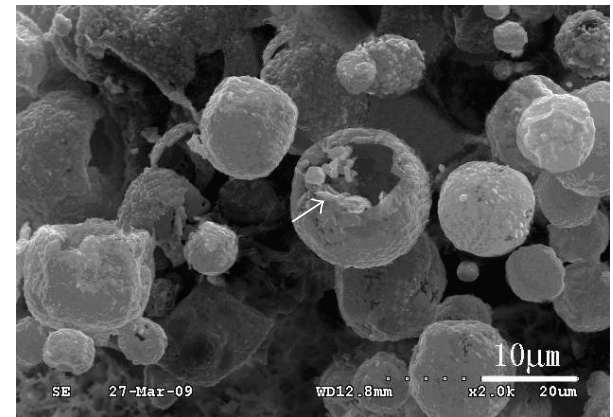

(c)

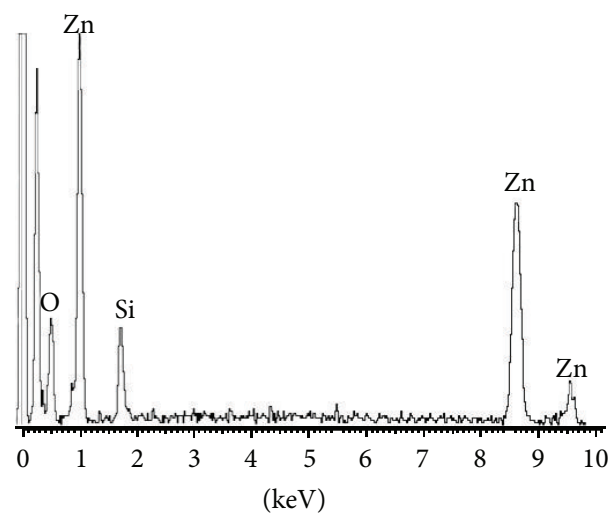

Full scale 168 cts cursor: $0.000 \mathrm{keV}$

(e)

FIGURE 3: Overview SEM image of hollow-like ZnO (a); typical SEM images of the hollow-like ZnO (b, c); typical HRTEM image of the hollow-like $\mathrm{ZnO}(\mathrm{d})$; and EDS spectrum of the as-obtained product (e).

further light on the structural features of hollow-sphere-like $\mathrm{ZnO}$, HRTEM analysis was carried out (Figure 3(d)). The observation reveals that their surfaces are rough, suggesting that the shells of hollow-sphere-like $\mathrm{ZnO}$ are composed of many small nanoparticles. Associated with Figure 4, energy dispersive spectrometer (EDS) analysis (Figure 3(e)) confirms that only $\mathrm{Zn}, \mathrm{O}$, and $\mathrm{Si}$ are present in the structures. $\mathrm{Si}$ element is from the underlay of Si slip. In addition, the calculated atomic ratio of $\mathrm{Zn}$ to $\mathrm{O}$ is close to $1: 1$ based on the data from Table 1, which agrees well with the stoichiometric composition of $\mathrm{ZnO}$.

The possible growth mechanism of hollow-sphere-like $\mathrm{ZnO}$ may follow the process as presented in Figure 5. The upper section is the SEM diagrams of the product prepared at different reaction stages, and the lower section is the schematic diagram of the change of product's structure 


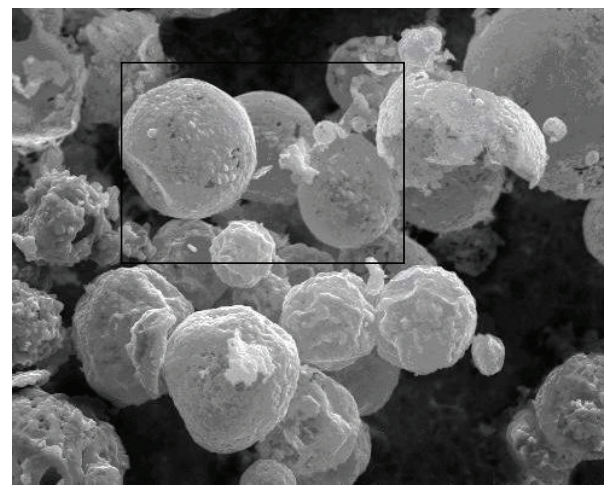

FIGURE 4: The selected area of hollow-like ZnO image for EDS measurement (rectangle part).

TABLE 1: Element content of hollow-like ZnO from EDS spectrum.

\begin{tabular}{lcc}
\hline Element & $\begin{array}{c}\text { Weight } \\
\text { percentage/\% }\end{array}$ & $\begin{array}{c}\text { Atom } \\
\text { percentage/\% }\end{array}$ \\
\hline Si K & 10.35 & 23.61 \\
Zn K & 69.36 & 38.72 \\
O K & 20.29 & 37.67 \\
Gross amount & $\mathbf{1 0 0 . 0 0}$ & $\mathbf{1 0 0 . 0 0}$ \\
\hline
\end{tabular}

during the reaction process. Due to the high purity of the $\mathrm{Zn}$ used, we do not expect that the other trace metals $(<0.0001 \%)$ have affected the formation of $\mathrm{ZnO}$ nuclei and the growth of hollow-sphere-like $\mathrm{ZnO}$ afterwards. Therefore, pure $\mathrm{Zn}$ powder firstly evaporated to $\mathrm{Zn}$ vapors in the $950^{\circ} \mathrm{C}$ furnace. But when the boat was dragged out from the long tube, air circulation was created between the long quartz tube and boat. And in the dragging process temperature decreased in the furnace because of the air circulation, resulting in lots of $\mathrm{Zn}$ vapors abruptly transforming into micro- or nanoZn droplets (Figure 5(I)) in the previous supersaturation of $\mathrm{Zn}$ vapor. The transforming process would not stop until a new equilibrium was obtained. These $\mathrm{Zn}$ droplets might assemble into larger sphere-shaped $\mathrm{Zn}$ clusters (or droplets) with different sizes. Of course, air circulation also brought in more oxygen and the surfaces of $\mathrm{Zn}$ clusters (droplets) were oxidized into different sizes of $\mathrm{ZnO}$ nanocrystallite islands as illustrated in Figure 5(II) due to nonuniform oxidization, which would cause continuous or discontinuous nanopores on the surfaces of the spheres. Figure 5(a) shows the SEM image of the product as irregular $\mathrm{ZnO}$ spheres with different sizes of $\mathrm{ZnO}$ nanocrystallite islands. As oxidization continued from the surface into the core of $\mathrm{Zn}$ clusters, the equilibrium between $\mathrm{Zn}$ vapor and micro- or nano- $\mathrm{Zn}$ liquid was shattered and micro- or nano-Zn liquid enveloped in the core of oxidized $\mathrm{Zn}$ clusters could be evaporated to supplement unsaturated $\mathrm{Zn}$ vapors from the nanopores as shown in Figure 5(III). As shown in Figure 5(b), several pores formed on the surface of $\mathrm{ZnO}$ spheres. Meanwhile, some evaporated $\mathrm{Zn}$ liquid might be oxidized near the pores and became thicker shells to plug up the previous nanopores, other $\mathrm{ZnO}$ liquid evaporated might rush out successfully to making pores bigger even causing holes (Figure 5(IV)). There is, certainly, also the alternative possibility that the surfaces of clusters were totally oxidized into $\mathrm{ZnO}$ nanocrystallite to form relative perfect $\mathrm{ZnO}$ sphere as shown in Figures 3(b) and $3(\mathrm{c})$. In addition, as outside temperature decreased, the evaporated $\mathrm{Zn}$ would generate higher pressure inside the $\mathrm{ZnO}$ sphere shell than that of outside. Some sphere clusters would even burst and explode into broken egg-shell $\mathrm{ZnO}$ because they could not stand the high pressure.

We believe that $\mathrm{Zn}$ vapors and micro- or nano-Zn liquid pursued dynamic equilibrium through the whole oxidation reaction till the exhausting of the last $\mathrm{Zn}$ liquid. It should be underlined, however, that though the above-mentioned oxidation process was carried out so fast (we drew out the quartz boat just in 10 seconds), the oxidation reaction of $\mathrm{Zn}$ forming hollow-sphere-like $\mathrm{ZnO}$ might be much faster. Moreover, some additional sub-ball- or sub-hollow-sphere $\mathrm{ZnO}$ deposited on the spheres near pores or holes confirmed that $\mathrm{Zn}$ vapors and micro- or nano-Zn droplets liquid transformed to each other easily according to the theory of $\mathrm{Xu}$ et al. [27]. However, total confirmation for this hypothesis still needs many more studies.

The room temperature PL spectrum of as-obtained hollow-sphere-like $\mathrm{ZnO}$, shown in Figure 6, was obtained using Xe light as the excitation source $(320 \mathrm{~nm})$. According to Figure 6, there is a weak UV emission peak at $385 \mathrm{~nm}$. The UV emission corresponds to the near-band edge emission. It can also be explained by the near and edge transition of the wide band gap, namely, the recombination of free excitons through an exciton-exciton collision process [28]. Furthermore, it can be clearly seen that there is a strong green emission at about $518 \mathrm{~nm}$ in the green emission region. Vanheusden et al. [29] have proved that the green emission is attributable to the single ionized oxygen vacancy in $\mathrm{ZnO}$ and results from the radiative recombination of a photogenerated hole with an electron occupying the oxygen vacancy. Therefore, it is reasonable to believe that there are a great fraction of oxygen vacancies in the hollow-sphere-like $\mathrm{ZnO}$. In the previous reports, crystal vacancies have a dramatic effect on the activity of catalyst [30, 31]. Thus, based on the results, the hollow-sphere-like $\mathrm{ZnO}$ may be a potential candidate for catalyst. 


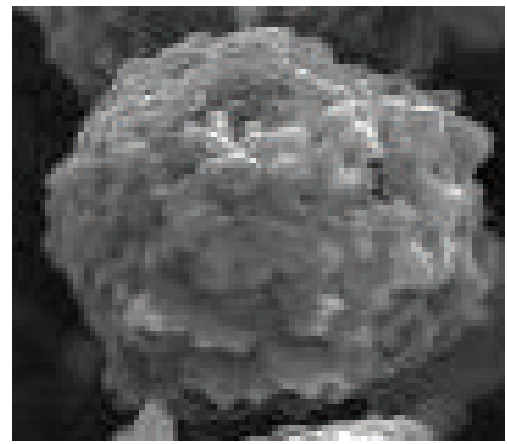

(a)

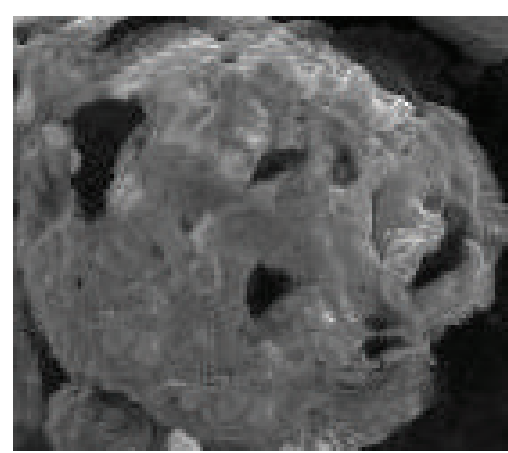

(b)

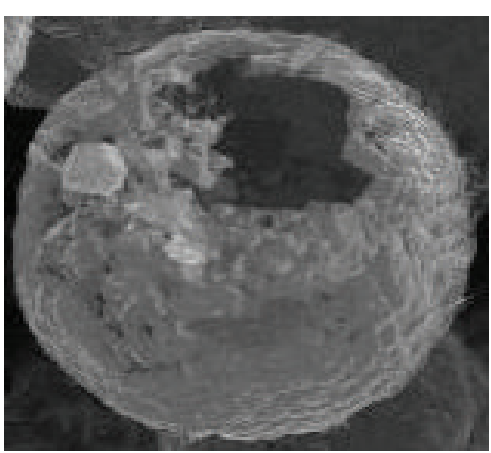

(c)

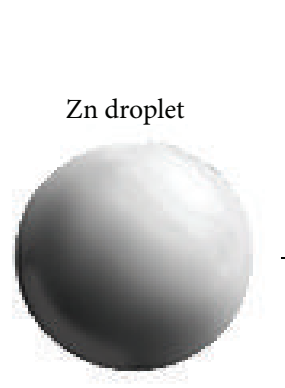

(I)

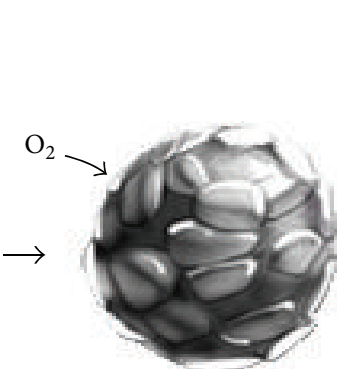

(II)

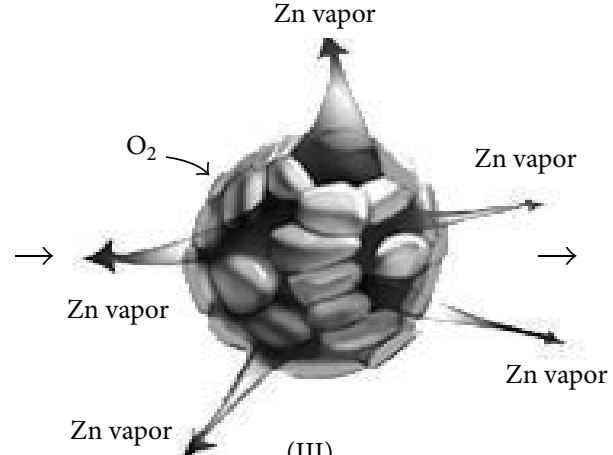

(III)

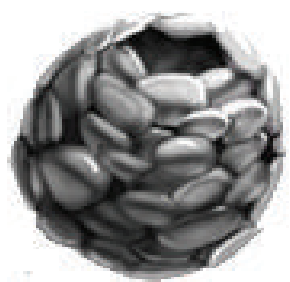

(IV)

FIGURE 5: Schematic illustration of the proposed growth mechanism for the formation of hollow-sphere-like ZnO. The upper section is the SEM diagrams of the product prepared at different reaction stages ((a) the second stage; (b) the third stage; (c) the fourth stage), and the lower section is the schematic diagram of the change of product's structure during the reaction process: (I) formation of $\mathrm{Zn}$ clusters; (II) surfaces of $\mathrm{Zn}$ clusters oxidized into nanocrystallite islands; (III) micro- or nano-Zn liquid in the core of Zn clusters evaporated to supply unsaturated $\mathrm{Zn}$ vapors from the nanopores; and (IV) formation of $\mathrm{ZnO}$ hollow sphere with nanopores or holes.

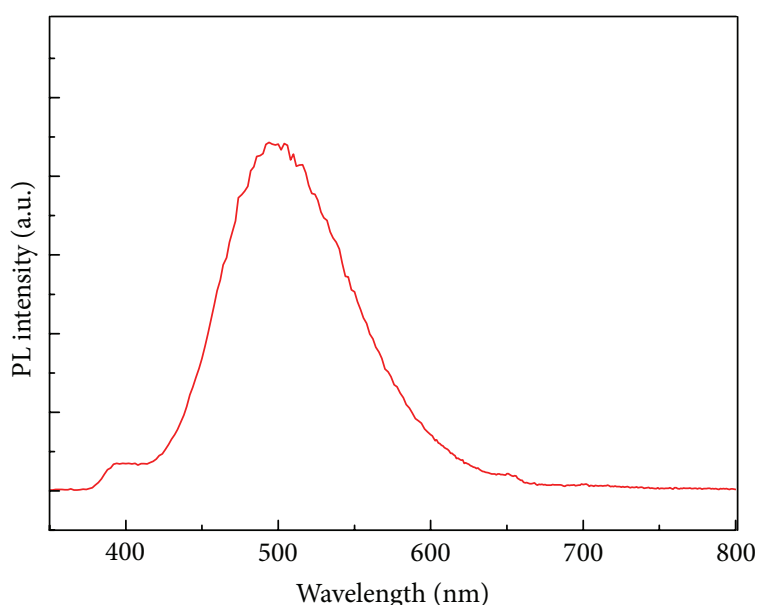

FIGURE 6: PL spectrum of the as-obtained hollow-sphere-like $\mathrm{ZnO}$ products.

\section{Conclusion}

In summary, we successfully prepared the hollow-sphere-like $\mathrm{ZnO}$ by facile combustion oxidization method without using any catalyst at the temperature of $950^{\circ} \mathrm{C}$. SEM images showed that the morphology of the as-obtained $\mathrm{ZnO}$ was nearly spherical with diameters ranging from $\sim 2 \mu \mathrm{m}$ to $\sim 15 \mu \mathrm{m}$ and some spheres had rough structures with small particles, pores, or holes. HRTEM image revealed that their surfaces were rough, suggesting that the shells of hollow-spherelike $\mathrm{ZnO}$ were composed of many small nanoparticles. The hollow-sphere-like $\mathrm{ZnO}$ should grow from $\mathrm{Zn}$ droplets controlled by dynamic equilibrium between $\mathrm{Zn}$ vapors and micro- or nano-Zn droplets liquid in violent oxidation conditions. Furthermore, the hollow-sphere-like $\mathrm{ZnO}$ exhibited a strong green emission which was accounted for by the greater number of ionized oxygen vacancies. Therefore we believe that the hollow-sphere-like $\mathrm{ZnO}$ material may be a good candidate for application in optical devices and catalyst systems.

\section{Conflict of Interests}

The authors declare that there is no conflict of interests regarding the publication of this paper.

\section{Acknowledgments}

The authors gratefully acknowledge financial support from NSFC (51901086, 51072118), the 973 program (2010CB234609), Shanghai Shuguang Project (09SG46), 
STCSM (10231201103), and the Innovation Fund Project for Graduate Student of Shanghai (JWCXSL1402).

\section{References}

[1] Z. Hong, Y. Xu, Y. Liu, and M. Wei, "Unique ordered $\mathrm{TiO}_{2}$ superstructures with tunable morphology and crystalline phase for improved lithium storage properties," Chemistry A, vol. 18, no. 34, pp. 10753-10760, 2012.

[2] S. H. Oh, R. Black, E. Pomerantseva, J. Lee, and L. F. Nazar, "Synthesis of a metallic mesoporous pyrochlore as a catalyst for lithium- $\mathrm{O}_{2}$ batteries," Nature Chemistry, vol. 4, no. 12, pp. 10041010, 2012.

[3] A. P. Alivisatos, "Semiconductor clusters, nanocrystals, and quantum dots," Science, vol. 271, no. 5251, pp. 933-937, 1996.

[4] I. C. Yao, P. Lin, and T. Y. Tseng, "Nanotip fabrication of zinc oxide nanorods and their enhanced field emission properties," Nanotechnology, vol. 20, no. 12, Article ID 125202, 2009.

[5] P. D. Yang, H. Q. Yan, S. Mao et al., "Controlled growth of $\mathrm{ZnO}$ nanowires and their optical properties," Advanced Functional Materials, vol. 12, no. 5, pp. 323-331, 2002.

[6] Z. L. Wang and J. Song, "Piezoelectric nanogenerators based on zinc oxide nanowire arrays," Science, vol. 312, no. 5771, pp. $243-$ 246, 2006.

[7] X. G. Liu, D. Y. Geng, P. J. Shang et al., "Fluorescence and microwave-absorption properties of multi-functional $\mathrm{ZnO}$ coated $\alpha$-Fe solid-solution nanocapsules," Journal of Physics D: Applied Physics, vol. 41, no. 17, Article ID 175006, 2008.

[8] M. S. Cao, X. L. Shi, X. Y. Fang et al., "Microwave absorption properties and mechanism of cagelike $\mathrm{ZnO} / \mathrm{SiO}_{2}$ nanocomposites," Applied Physics Letters, vol. 91, no. 20, Article ID 203110, 2007.

[9] M. S. Cao, W. Zhou, X. L. Shi, and Y. J. Chen, "Dynamic response and reinforcement mechanism of composites embedded with tetraneedlelike ZnO nanowhiskers," Applied Physics Letters, vol. 91, no. 2, Article ID 021912, 2007.

[10] Z. L. Wang, X. Y. Kong, Y. Ding et al., "Semiconducting and piezoelectric oxide nanostructures induced by polar surfaces," Advanced Functional Materials, vol. 14, no. 10, pp. 943-956, 2004.

[11] D. H. Xu, Z. B. Deng, Y. Xu et al., "An anode with aluminum doped on zinc oxide thin films for organic light emitting devices," Physics Letters A: General, Atomic and Solid State Physics, vol. 346, no. 1-3, pp. 148-152, 2005.

[12] M. Willander, Q. X. Zhao, Q.-H. Hu et al., "Fundamentals and properties of zinc oxide nanostructures: optical and sensing applications," Superlattices and Microstructures, vol. 43, no. 4, pp. 352-361, 2008.

[13] I. Gilbert and R. Freer, "Donor and acceptor doping of zinc oxide varistors," Journal of Physics Condensed Matter, vol. 14, no. 4, pp. 945-954, 2002.

[14] W. J. E. Beek, M. M. Wienk, and R. A. J. Janssen, "Efficient hybrid solar cells from zinc oxide nanoparticles and a conjugated polymer," Advanced Materials, vol. 16, no. 12, pp. 10091013, 2004.

[15] W. C. Liu and W. Cai, "Synthesis and characterization of $\mathrm{ZnO}$ nanorings with $\mathrm{ZnO}$ nanowires array aligned at the inner surface without catalyst," Journal of Crystal Growth, vol. 310, no. 4, pp. 843-846, 2008.

[16] Z. L. Wang, "Nanobelts, nanowires, and nanodiskettes of semiconducting oxides-from materials to nanodevices," Advanced Materials, vol. 15, no. 5, pp. 432-436, 2003.
[17] Z. L. Wang, "Novel nanostructures of $\mathrm{ZnO}$ for nanoscale photonics, optoelectronics, piezoelectricity, and sensing," Applied Physics A: Materials Science and Processing, vol. 88, no. 1, pp. 7-15, 2007.

[18] R. F. Zhuo, H. T. Feng, J. T. Chen et al., "Multistep synthesis, growth mechanism, optical, and microwave absorption properties of $\mathrm{ZnO}$ dendritic nanostructures," Journal of Physical Chemistry C, vol. 112, no. 31, pp. 11767-11775, 2008.

[19] W. Liu and W. Cai, "One-dimensional and quasi-one-dimensional $\mathrm{ZnO}$ nanostructures prepared by spray-pyrolysisassisted thermal evaporation," Applied Surface Science, vol. 254, no. 10, pp. 3162-3166, 2008.

[20] C. Y. Liu, H. Y. Li, W. Q. Jie, X. Z. Zhang, and D. P. Yu, "Preparation of $\mathrm{ZnO}$ cluster and rod-like whiskers through hydrothermal methods," Materials Letters, vol. 60, no. 11, pp. 1394-1398, 2006.

[21] M. J. Zheng, L. D. Zhang, G. H. Li, and W. Z. Shen, "Fabrication and optical properties of large-scale uniform zinc oxide nanowire arrays by one-step electrochemical deposition technique," Chemical Physics Letters, vol. 363, no. 1-2, pp. 123$128,2002$.

[22] X. G. Liu, "Zinc oxide nano- and microfabrication from coordination-polymer templates," Angewandte Chemie-International Edition, vol. 48, no. 17, pp. 3018-3021, 2009.

[23] A. B. Djurišić, Y. H. Leung, W. C. H. Choy, K. W. Cheah, and W. K. Chan, "Visible photoluminescence in $\mathrm{ZnO}$ tetrapod and multipod structures," Applied Physics Letters, vol. 84, no. 14, pp. 2635-2638, 2004.

[24] J. Y. Lao, J. Y. Huang, D. Z. Wang, and Z. F. Ren, “ZnO nanobridges and nanonails," Nano Letters, vol. 3, no. 2, pp. 235238, 2003.

[25] G. Shen, J. H. Cho, and C. J. Lee, "Morphology-controlled synthesis, growth mechanism and optical properties of $\mathrm{ZnO}$ nanonails," Chemical Physics Letters, vol. 401, no. 4-6, pp. 414419, 2005.

[26] Z. Deng, M. Chen, G. X. Gu, and L. M. Wu, "A facile method to fabricate $\mathrm{ZnO}$ hollow spheres and their photocatalytic property," Journal of Physical Chemistry B, vol. 112, no. 1, pp. 16-22, 2008.

[27] L. L. Xu, P. Q. Zhao, X. L. Wu et al., "Synthesis of ZnO eggshelllike hollow spheres via thermal evaporation at low temperature," Journal of Physics D: Applied Physics, vol. 40, no. 15, pp. 46214624, 2007.

[28] Y. C. Kong, D. P. Yu, B. Zhang, W. Fang, and S. Q. Feng, "Ultraviolet-emitting $\mathrm{ZnO}$ nanowires synthesized by a physical vapor deposition approach," Applied Physics Letters, vol. 78, no. 4, article 407, 2001.

[29] K. Vanheusden, W. L. Warren, C. H. Seager, D. K. Tallant, J. A. Voigt, and B. E. Gnade, "Mechanisms behind green photoluminescence in $\mathrm{ZnO}$ phosphor powders," Journal of Applied Physics, vol. 79, pp. 7983-1990, 1996.

[30] C.-K. Loong and M. Ozawa, "The role of rare earth dopants in nanophase zirconia catalysts for automotive emission control," Journal of Alloys and Compounds, vol. 303-304, pp. 60-65, 2000.

[31] L. Spanhel, M. Haase, H. Weller, and A. Henglein, "Photochemistry of colloidal semiconductors. 20. Surface modification and stability of strong luminescing CdS particles," Journal of the American Chemical Society, vol. 109, no. 19, pp. 5649-5655, 1987. 

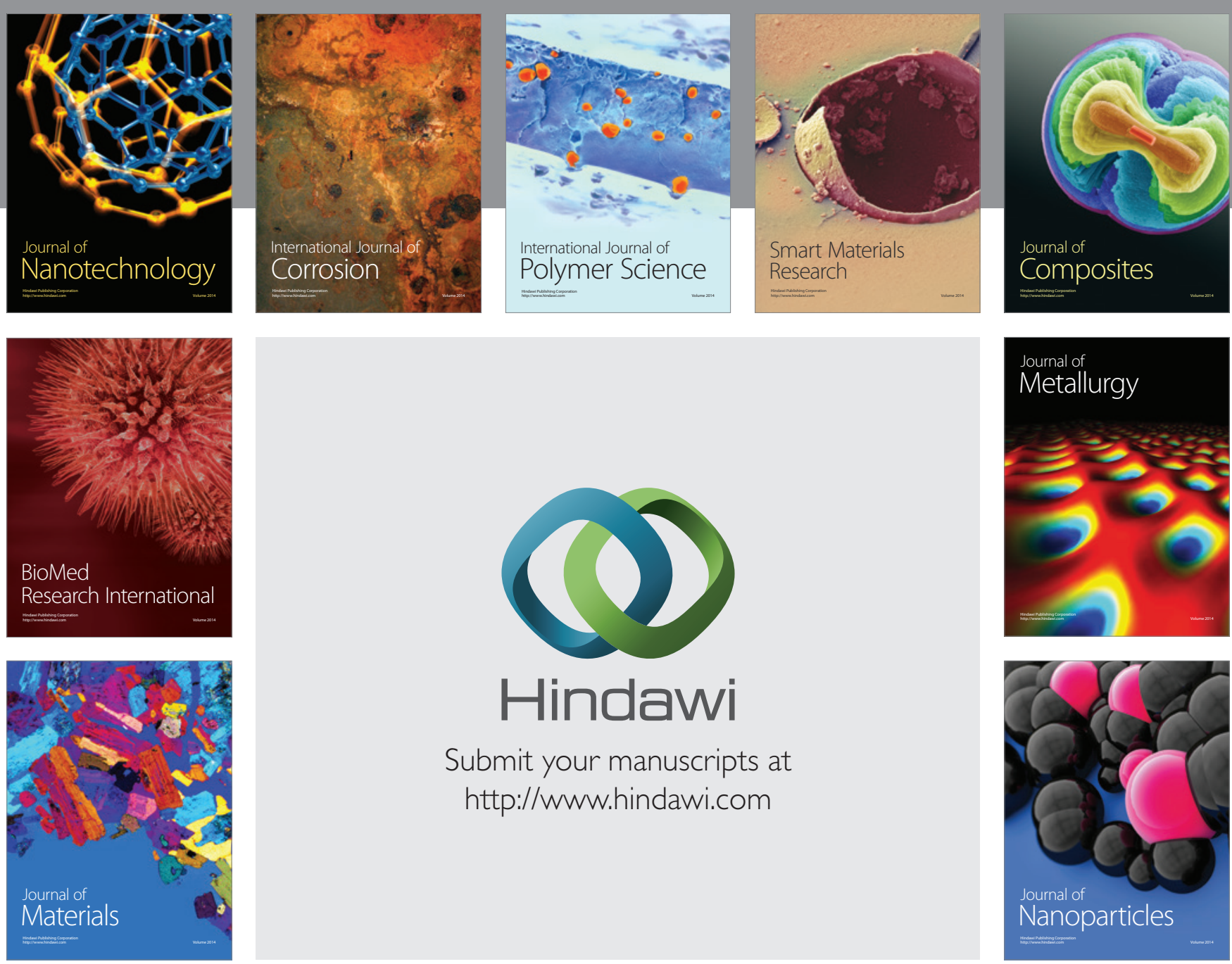

Submit your manuscripts at http://www.hindawi.com
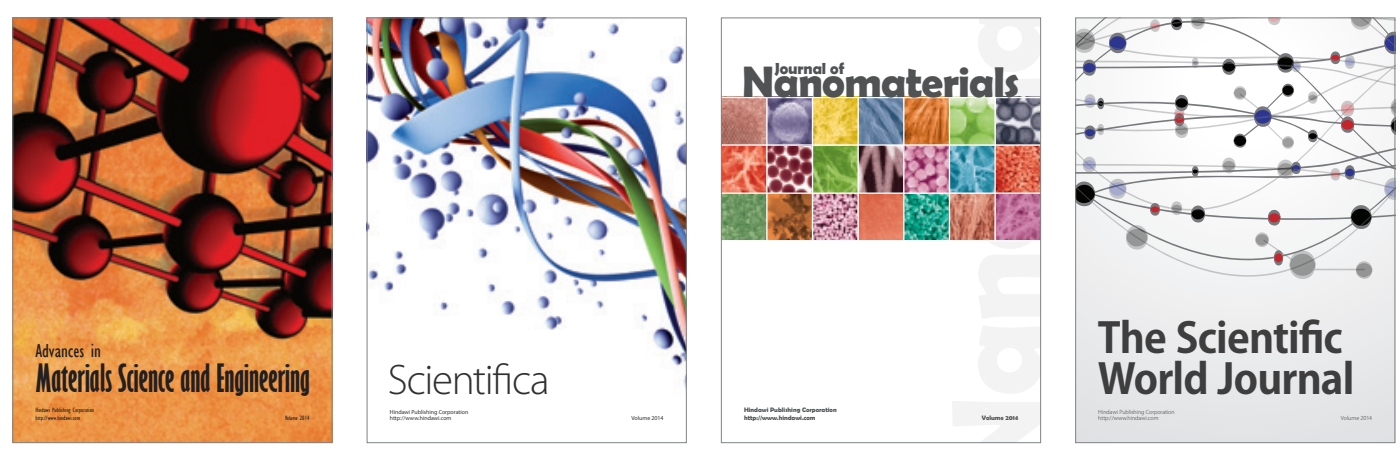

\section{The Scientific World Journal}
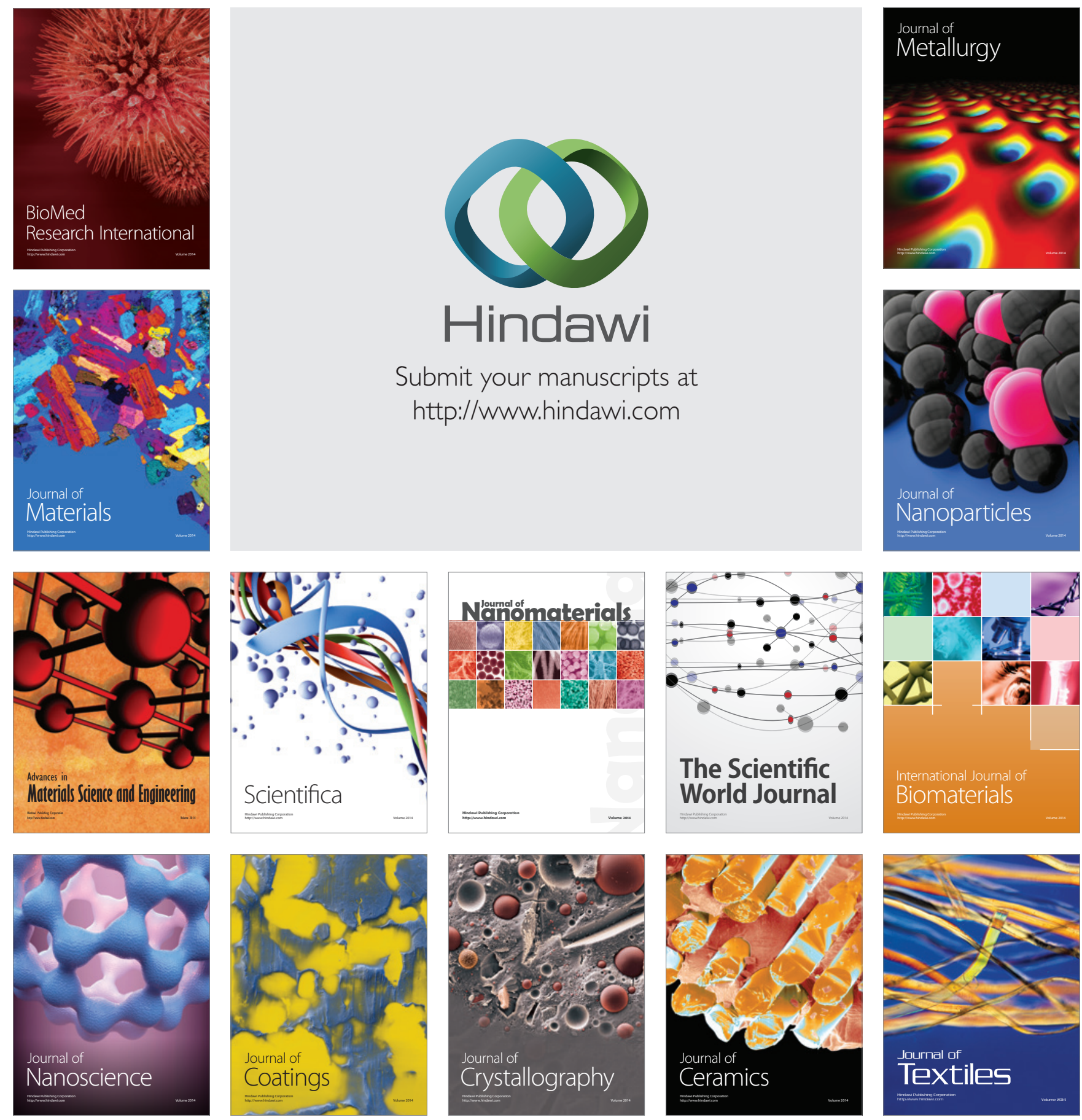